\title{
CFD Model for Emulsification of Slag into the Steel
}

\author{
Petri SULASALMI, Aki KÄRNÄ, Timo FABRITIUS and Jari SAVOLAINEN \\ Laboratory of Process Metallurgy, University of Oulu, P. O. Box 4300, FIN-90014 University of Oulu, Finland. \\ E-mail: petri.sulasalmi@oulu.fi
}

(Received on May 8, 2009; accepted on July 29, 2009)

\begin{abstract}
A CFD model based on water model experiments has been created to simulate slag entrainment and droplet formation. Multiphase Volume of Fluid (VOF) method is used to track the interface between slag and steel and User Defined File (UDF) code is applied to track separate droplets. Four oil-water systems and three slag-metal systems were simulated. The main objective of this research was to obtain droplet diameter distributions and the average droplet diameter in several different cases. With slag-metal cases the main interest was the effect of interfacial tension to droplet formation. With oil-water systems we studied the effect oil layer width and oil viscosity. The obtained droplet diameter distributions show that the dominant droplet size is $2-3 \mathrm{~mm}$ in every oil-water systems. In slag-metal systems the dominant size varies between $1-2 \mathrm{~mm}$ and $2-3 \mathrm{~mm}$. The simulations show also that the average droplet size in all cases is 2.78-3.63 $\mathrm{mm}$. The results were compared to the studies available in the literature.
\end{abstract}

KEY WORDS: emulsification; slag entrainment; droplet formation; droplet size; CFD model.

\section{Introduction}

Intensive emulsification of slag into the steel can accelerate chemical reactions and therefore it has utilised to strengthen refining processes. For example effective desulphurisation is possible achieve using correct slag composition and intensive gas stirring due to the emulsified slag droplets. Optimal physical properties of slag and sufficient velocity of steel is needed to generate reaction area between the slag and the steel.

Role of the physical properties of the fluids on the emulsification and the size of entrained droplets have been studied by water models. ${ }^{1-5)}$ Cramb and Jimbo ${ }^{3)}$ discovered that the interfacial energy between liquid slag and steel is a key factor in determining the emulsification. They estimated based on the interfacial and buoyant energy calculation that surface energy that can be described by interfacial tension between slag and steel is the dominant factor effecting on the emulsification. According to the Harman and Cramb ${ }^{4}$ and Savolainen et $a .^{5)}$ the diameter of entrained droplets were increased when interfacial tension was increased.

The effect of physical properties of fluid on mass transfer during emulsification have been studied by Wei and Oeters $^{6)}$ and Mietz et $a l^{7}{ }^{7}$ According to the their experiments and mathematical model, the amount and size of formed droplets mainly depend on the flow of kinetic energy to the thin slag layer accelerated by momentum transfer from metal to slag. ${ }^{6,7)}$ They derived the equation for the droplet size from the force balance and measured size distribution of droplets in water-cyclohexane system. ${ }^{6)}$ Iguchi et $a l .{ }^{8)}$ have also developed empirical relation for the entrainment of slag into the steel based on the cold model study simulating the ladle environment. In their study the diameter of entrained droplets are calculated by Asai's equation based on the energy needed to form the droplet and to overcome buoyancy. ${ }^{9}$

Lachmund et al. ${ }^{10)}$ have generated a numerical model for desulphurisation in an industrial ladle which takes all relevant process parameters into account. Furthermore, Xiao et al. ${ }^{11)}$ have studied entrainment phenomena by the water model and the mathematical one. They defined criterion on the occurrence of emulsification using the modified Weber number which takes not the size of the formed droplets into account. ${ }^{11)}$ Jonsson and Jönsson ${ }^{12)}$ and Andersson et al. ${ }^{13)}$ have used this criterion in their CFD models to simulate emulsification during ladle treatment.

Although the effects of physical properties of fluids on the emulsification have been published, there is a need for a useful model to simulate average droplet size, size distribution and reaction area between steel and slag depending on the physical properties of a slag. In this paper the effects of the most important physical properties and the thickness of the lighter phase on the size distribution and average size of emulsified droplets in water-oil and steel-slag systems were studied. Furthermore, the sub-model for average droplet size and diameter distribution.

\section{Experimental Setup}

The model box used in physical modelling $(0.51 \mathrm{~m}$, $0.148 \mathrm{~m}$ and $0.10 \mathrm{~m}$ ) was made of acryl plastic. The total height of the used oil- $\mathrm{H}_{2} \mathrm{O}$-solution is set to be $0.087 \mathrm{~m}$. For more detailed description of the setup see Ref. 5). The physical model can be seen in Fig. 1.

Three different oils and $\mathrm{H}_{2} \mathrm{O}$ was used in the experiments. Experiments were made with three $(0.005 \mathrm{~m}$, 


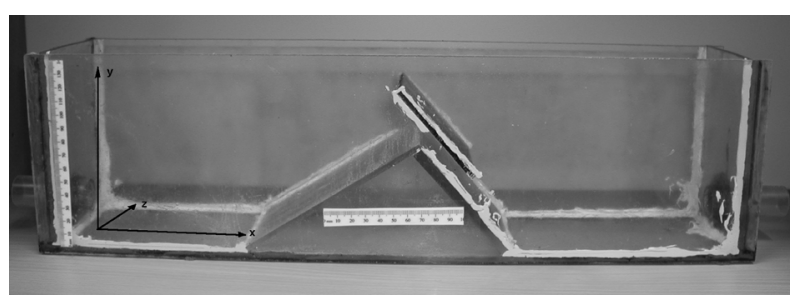

Fig. 1. Physical model the dimensions of the model are: $0.51 \mathrm{~m}$ in $x$-direction, $0.148 \mathrm{~m}$ in $y$-direction and $0.1 \mathrm{~m}$ in $z$-direction.

$0.010 \mathrm{~m}$ and $0.015 \mathrm{~m}$ ) thicknesses of lighter phase (oil). The results of experiments were presented in detail in our previous work. ${ }^{5)}$

Physical model was used to determine the critical velocities for oil (slag) emulsification and diameters of entrained droplets. These results were used to validate CFD modellings in the present study.

\section{Model Description}

The main idea of simulating the physical experiments was to be able to track every droplet and collect the data concerning droplet diameters and droplet diameter distribution to create a fundamental based model for emulsification.

\subsection{The Volume Of Fluid Method}

Tracking of an interface between two phases is calculated by using the VOF (Volume Of Fluid) model. The VOF model can model two or more immiscible fluids by solving a single set of momentum equations and tracking the volume fraction of each of the fluids throughout the domain.

When using the VOF model for each additional phase a variable is introduced: the volume fraction in the computational cell. In each control volume the sum of the volume fractions is equal to 1 . If $q$ th fluid's volume fraction is denoted by $\alpha_{q}$ then three following conditions are possible:

1. $\alpha_{q}=0$, i.e. the cell is empty of the $q$ th fluid.

2. $\alpha_{q}=1$, i.e. the cell is full of the $q$ th fluid.

3. $0<\alpha_{q}<1$, the cell contains the interface between the $q$ th fluid and one or more other fluids.

Based on the local value of $\alpha_{q}$, the appropriate properties and variables will be assigned to each of control volume within the domain.

\subsection{Equations}

The following equations were solved during the simulation of the fluid flow and interfaces.

\section{Volume Fraction Equation}

The continuity equation for the volume fraction of the phases is given below. Solution of this equation accomplishes the tracking of the interfaces between phases.

$$
\frac{1}{\rho_{q}} \cdot\left(\frac{\partial}{\partial t}\left(\alpha_{q} \cdot \rho_{q}\right)+\nabla \cdot\left(\alpha_{q} \cdot \rho_{q} \cdot \vec{v}_{q}\right)\right)=0
$$

The volume fraction equation was solved only for the secondary phases (gas, slag) and the primary phase volume fraction was computed based on the following equation:

$$
\sum_{q=1}^{3} \alpha_{q}=1
$$

\section{Material Properties}

The transport equations include terms for the material properties, i.e. density and viscosity. These properties were determined by the presence of the component phases in each control volumes. Let $\alpha_{m}, \alpha_{s}$ and $\alpha_{g}$ be the volume fractions of metal, slag and gas phases, respectively. Then, in any given comptational cell the density, for example, is computed as

$$
\rho=\alpha_{m} \cdot \rho_{m}+\alpha_{s} \cdot \rho_{s}+\alpha_{g} \cdot \rho_{g}
$$

Every material property was computed in a similar fashion.

\section{Momentum Equation}

VOF method solves a single momentum equation throughout the comptational domain. The resulting field is shared among the phases. The Eq. (4), shown below, depends on the volume fractions of all phases through material properties (density $\rho$ and viscosity $\mu$ ).

$$
\begin{aligned}
& \frac{\partial}{\partial t}(\rho \cdot \vec{v})+\nabla \cdot(\rho \cdot \vec{v} \cdot \vec{v}) \\
& \quad=-\nabla p+\nabla \cdot\left(\mu \cdot\left(\nabla \vec{v}+\nabla \vec{v}^{T}\right)\right)+\rho \cdot \vec{g}+\vec{F}
\end{aligned}
$$

where $\vec{v}$ is the velocity vector, $\vec{g}$ is the gravitational force vector, $\mu$ is the dynamic viscosity and $\rho$ is the density.

\section{Turbulence Model}

The slag-metal cases were calculated using turbulence model. The turbulence model that was used is LES (Large Eddy Simulation) which is a proper choice when using a very fine grid. In LES, large eddies are resolved directly and small eddies are modeled.

The governing equations employed for LES are obtained by filtering the time-dependent Navier-Stokes equations. The filtering process effectively filters out the eddies whose scale are smaller than the filter width or grid spacing used in computations. The resulting equations thus govern the dynamics of large eddies.

A filtered variable is defined by

$$
\bar{\varphi}(x)=\int_{D} \varphi\left(x^{\prime}\right) \cdot G\left(x, x^{\prime}\right) d x^{\prime}
$$

where $D$ is the fluid domain and $G$ is the filter function that determines the scale of the resolved eddies. In our case the filtering operation is done as

$$
\bar{\varphi}(x)=\frac{1}{V} \int_{v} \varphi\left(x^{\prime}\right) d x^{\prime}, \quad x \in v
$$

where $V$ is the volume of a computational cell. The filter function here is then

$$
G\left(x, x^{\prime}\right)= \begin{cases}1 / V, & x^{\prime} \in v \\ 0, & \text { otherwise }\end{cases}
$$

Filtering the Navier-Stokes equations, one obtains 


$$
\begin{gathered}
\frac{\partial \rho}{\partial t}+\frac{\partial}{\partial x_{i}}\left(\rho \bar{u}_{i}\right)=0 \ldots \ldots \ldots . . . . . \\
\frac{\partial}{\partial t}\left(\rho \cdot \bar{u}_{i}\right)+\frac{\partial}{\partial x_{i}}\left(\rho \cdot \bar{u}_{i} \cdot \bar{u}_{j}\right) \\
=\frac{\partial}{\partial x_{j}}\left(\mu \cdot \frac{\partial \sigma_{i j}}{\partial x_{j}}\right)-\frac{\partial \bar{p}}{\partial x_{i}}-\frac{\partial \tau_{i j}}{\partial x_{j}}
\end{gathered}
$$

where $\sigma_{i j}$ is the stress tensor due to molecular viscosity defined by

$$
\sigma_{i j}=\mu \cdot\left(\frac{\partial \bar{u}_{i}}{\partial x_{j}}+\frac{\partial \bar{u}_{j}}{\partial x_{i}}\right)-\frac{2}{3} \cdot \mu \cdot \frac{\partial \bar{u}_{l}}{\partial x_{l}} \cdot \delta_{i j} \ldots \ldots . .
$$

and $\tau_{i j}$ is the subgrid-scale stress defined by

$$
\tau_{i j}=\rho \cdot \overline{u_{i} \cdot u_{j}}-\rho \cdot \bar{u}_{i} \cdot \bar{u}_{j}
$$

The subgrid-scale stresses resulting from the filtering operation are unknown, and require modeling. The subgridscale turbulent stresses were computed from

$$
\tau_{i j}-\frac{1}{3} \cdot \tau_{k k} \cdot \delta_{i j}=-2 \cdot \mu_{t} \cdot \bar{S}_{i j}
$$

where $\mu_{t}$ is the subgrid-scale turbulent viscosity. The isotropic part $\tau_{k k}$ is not modeled but added to the filtered static pressure term. $\bar{S}_{i j}$ is the rate-of-strain tensor for the resolved scale defined by

$$
\bar{S}_{i j}=\frac{1}{2} \cdot\left(\frac{\partial \bar{u}_{i}}{\partial x_{j}}+\frac{\partial \bar{u}_{j}}{\partial x_{i}}\right)
$$

The subgrid-scale turbulent viscosity is modeled by using the Smagorinsky-Lilly model. ${ }^{14)}$

\section{Computational Domain and Description of the Cases}

The computational mesh was structured non-uniform mesh, including total 559320 hexahedral control volumes. The mesh can be seen in Fig. 2. The grid is very fine so that the resolution is high enouhg that small droplets (appr. $2 \mathrm{~mm}$ ) could be tracked. It follows that calculating is very time consuming.

Several different oil- $\mathrm{H}_{2} \mathrm{O}$-cases were simulated and also three cases using the properties (density, viscosity, interfacial tensions, surface tensions) of steel, slag and argon gas. Physical properties of fluids used in simulations are presented in Table 1.

Typical AOD process at $1700^{\circ} \mathrm{C}$ was studied by cases 5-7 simulating slag reduction period when slag is emulsified into the steel melt. Composition of slag after slag reduction period is assumed to be $55 \% \mathrm{CaO}-28 \% \mathrm{SiO}_{2}-$ $8 \% \mathrm{MgO}-2 \% \mathrm{Al}_{2} \mathrm{O}_{3}-7 \% \mathrm{CaF}_{2}{ }^{15)}$ Viscosity of slag is approximated to be 0.18 Pas. ${ }^{16)}$ Velocity of steel was determined by CFD model. ${ }^{17)}$ According to the CFD simulations velocity of steel at the vicinity of steel-slag interface is approximately $0.8 \mathrm{~m} / \mathrm{s}$ with usual process gas flow rates. Three different values for interfacial tension between steel and slag were used. Interfacial tension was calculated by Girifalco and Good's equation. ${ }^{18)}$ Surface tension of slag during reduction period was defined using the model derived by Tanaka et al. ${ }^{19)}$ Surface tension of steel is calculated by model based on modified form of Butler's equation. ${ }^{20)}$ Situation with low oxygen and sulphur contents of steel was simulated in Case 7. Interfacial tension was decreased in Cases 5 and 6 simulating on the change of steel composition and reaction between steel and slag.

\section{Results}

Main focus was to simulate the entrainment of oil and slag droplets. The purpose of this study is to study the effect oil and slag properties and interfacial tension between phases (oil-water or slag-metal) to the droplet formation and droplet size.

After the simulations were done an UDF-code was applied to the saved data files. The code recognises droplets and stores the volume of every droplet. The code goes through every cell in the domain and gives an id for every cell that is full of slag/oil phase, i.e. the volume fraction of

\begin{tabular}{|c|c|c|c|c|c|c|c|}
\hline & Case 1 & Case2 & Case 3 & Case 4 & Case 5 & Case 6 & Case 7 \\
\hline Viscosity (Oil), $\mathrm{Pa} \cdot \mathrm{s}$ & 0.06134 & 0.06134 & 0.1498 & 0.1498 & - & - & - \\
\hline Viscosity (Water), Pa.s & 0.00088 & 0.00088 & 0.00088 & 0.00088 & - & - & - \\
\hline Viscosity (Slag), Pa.s & - & - & - & - & 0.18 & 0.18 & 0.18 \\
\hline Viscosity (Metal), Pa.s & - & - & - & - & 0.0049 & 0.0049 & 0.0049 \\
\hline Density (Water), $\mathrm{kg} / \mathrm{m}^{3}$ & 997.0 & 997.0 & 997.0 & 997.0 & - & - & - \\
\hline Density (Oil), $\mathrm{kg} / \mathrm{m}^{3}$ & 903.0 & 903.0 & 867.0 & 867.0 & - & - & - \\
\hline Density (Slag), $\mathrm{kg} / \mathrm{m}^{3}$ & - & - & - & - & 2650.0 & 2650.0 & 2650.0 \\
\hline Density (Metal), $\mathrm{kg} / \mathrm{m}^{3}$ & - & - & - & - & 6500.0 & 6500.0 & 6500.0 \\
\hline Interfacial tension, $\mathrm{N} / \mathrm{m}$ & 0.01304 & 0.01304 & 0.01295 & 0.01295 & 0.5 & 0.75 & 1.05 \\
\hline Velocity, m/s & 0.285 & 0.324 & 0.361 & 0.444 & 0.8 & 0.8 & 0.8 \\
\hline $\begin{array}{l}\text { Widht of the slag/oil layer, } \\
\mathrm{m}\end{array}$ & 0.005 & 0.015 & 0.005 & 0.015 & 0.015 & 0.015 & 0.015 \\
\hline
\end{tabular}
slag/oil phase is $\alpha_{s}=1$. There droplets are clusters of cells

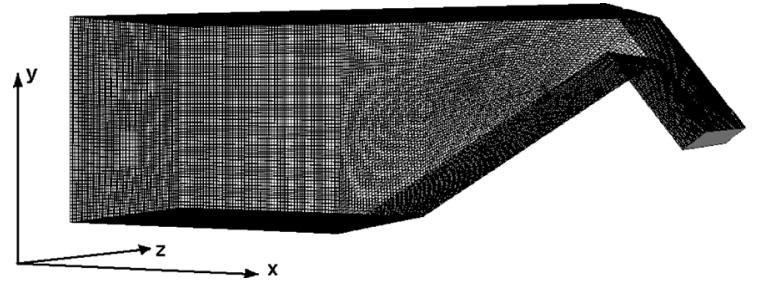

Fig. 2. The geometry and grid of the studied system. The dimensions of the domain are: 0.3006 in $x$-direction, $0.1 \mathrm{~m}$ in $y_{-}$ direction and $0.1 \mathrm{~m}$ in $z$-direction.

Table 1. The physical properties of fluids. 
full of slag/oil, i.e. if there is a cell such that $\alpha_{s}=1$ in it, the neighbouring cells with this property are given the same id. Thus, a droplet consists of a group of cells with the same id.

The droplets are all assumed to be ball shaped and since the volume is known the radius $r$ of a droplet can be calculated from the Eq. (13)

$$
V=\frac{4}{3} \cdot \pi \cdot r^{3} \Rightarrow r=\left(\frac{3 \cdot V}{4 \cdot \pi}\right)^{1 / 3}
$$

The code outputs the amount of droplets and the average droplet diameter in every saved time step. It also gives the diameter distribution and total area formed by the droplets in every saved time step.

\subsection{Oil-Water Systems}

For this study four different oil-water systems were simulated. In Fig. 3 can be seen a situation in Case 1. The red colour denotes the oil phase. The Fig. 3 demonstrates clearly simulated entrainment of oil droplets. The Fig. 4 represents a similar situation in the physical model. In the Figures $n$ is the total number of droplets at that time-step. Obtaining droplet size distributions was one of the main tasks. In all four oil-water cases the distributions are analogous. At very early stages (Fig. 5) the dominant diameter size of entrained droplets is $1-2 \mathrm{~mm}$ diameter. This rapidly changes toward 2-3 mm. After $3.5 \mathrm{~s}$ in both cases where the width of the oil layer was $15 \mathrm{~mm}$ (Case 2 and Case 4), about $50 \%$ of the droplets are of diameter 2-3 mm (Fig. 6).

Also in other two cases, with oil layer of $5 \mathrm{~mm}$, the same tendency obvious. Although the change towards wider diameter is somewhat slower, especially in the Case 1 where the viscosity of oil is smaller.

The Fig. 7 shows that after $7.5 \mathrm{~s}$ in all cases the dominant droplet diameter is $2-3 \mathrm{~mm}$. From that point onwards the shape of the diameter distribution in every case remains quite similar. Approximately 50 to $70 \%$ of droplets are of diameter $2-3 \mathrm{~mm}$. Percentage of droplets of diameter $1-2 \mathrm{~mm}$ after $7.5 \mathrm{~s}$ varies from 9 to $27 \%$. Droplets of size of $3-4 \mathrm{~mm}$ consist of 10 to $15 \%$ of total amount. Percentage of $5 \mathrm{~mm}$ or larger droplets is less than $20 \%$. The total amount of droplets is between 50 and 350 .

\subsection{Slag-Metal Systems}

For comparison, three cases were simulated using physical properties of slag and metal. Other properties but interfacial tension between slag and metal were constant. The purpose of this was to study the effect of interfacial tension on the emulsion. It will be seen that the effect is quite significant to droplet diameter distribution but especially to the amount of entrained droplets.

In the Figs. 9, 10, and 11, the distributions are presented at three different times. Although the size of droplets seems to be almost the same as in the oil-water systems, the diameter distribution doesn't seem to behave quite similarly. As one saw in the previous section the dominant diameter in oil-water systems changed from $1-2 \mathrm{~mm}$ to $2-3 \mathrm{~mm}$ rather quickly. In slag-metal cases the dominant size changes back and forth between 1-2 mm and 2-3 mm in Cases 6 and 7. In Case 5, in which the interfacial tension is lowest, the dominant size changes fast to the larger diameter interval, $2-3 \mathrm{~mm}$. And the size, in this case, remains as such.

In Case 6 and Case 7 the dominant size continues to change between 1-2 $\mathrm{mm}$ and 2-3 $\mathrm{mm}$. The absolute amount of droplet varies strongly in Case 6 and Case 7, dropping under ten droplets at times. While the amount at highest in Case 6 is around 70-100 droplets and in Case 7 around 40. Whenever the amount is not very low the dominant size is 2-3 mm.

\section{Discussion}

Based on the droplet data given by the present CFDmodel it was straightforward to calculate the weighted average of droplet diameter in every case. Equation (14) gives an approximation to the average droplet diameter $d^{*}$

$$
\begin{aligned}
& d^{*}=-63.05 \cdot h+0.92 \cdot \sigma-14.37 \cdot \mu_{s}-0.001 \cdot \Delta \rho \\
& +14.93 \cdot v_{\text {crit }}
\end{aligned}
$$

where $h$ is the width of oil/slag layer, $\mu_{s}$ is viscosity of oil/slag, $\sigma$ is the interfacial tension, $\Delta \rho$ is the density difference and $v_{\text {crit }}$ is the critical velocity. The Eq. (14) is a linear fitting to the average diameters in Cases 1-7. The data used deriving Eq. (14) is represented in Table 2. The Eq. (14) is obtained when the following system of equations is solved:

$$
\begin{gathered}
\left(\begin{array}{lllrl}
0.005 & 0.01304 & 0.0613 & 94.0 & 0.285 \\
0.005 & 0.01295 & 0.1498 & 130.0 & 0.361 \\
0.015 & 0.01304 & 0.0613 & 94.0 & 0.324 \\
0.015 & 0.01295 & 0.1498 & 130.0 & 0.444 \\
0.015 & 0.50 & 0.18 & 4150.0 & 0.8 \\
0.015 & 0.75 & 0.18 & 4150.0 & 0.8 \\
0.015 & 1.05 & 0.18 & 4150.0 & 0.8
\end{array}\right) \cdot\left(\begin{array}{l}
a \\
b \\
c \\
d \\
e
\end{array}\right) \\
=\left(\begin{array}{l}
2.78 \\
2.95 \\
3.06 \\
3.13 \\
3.12 \\
3.38 \\
3.63
\end{array}\right) \Rightarrow\left(\begin{array}{l}
a \\
b \\
c \\
d \\
e
\end{array}\right)=\left(\begin{array}{c}
-63.05 \\
0.92 \\
-14.37 \\
-0.001 \\
14.93
\end{array}\right)
\end{gathered}
$$

There are several articles made which include equations for droplet diameter. Common to these is that viscosity of any fluid is not taken into equation as a variable. Wei and Oeters have derived an equation for the droplet radius when in the case of critical velocity ${ }^{6}$

$$
r_{d, \mathrm{crit}}=\left(\frac{3}{2} \cdot \frac{\sigma}{g \cdot\left(\rho_{m}-\rho_{s}\right) \cdot \cos \alpha}\right)^{1 / 2}
$$

Asai ${ }^{10)}$ has also derived an equation for the average droplet size

$$
d_{p, c}=2 \cdot\left(\frac{3 \cdot \sigma}{g\left(\rho_{m}-\rho_{s}\right)}\right)^{1 / 2}
$$




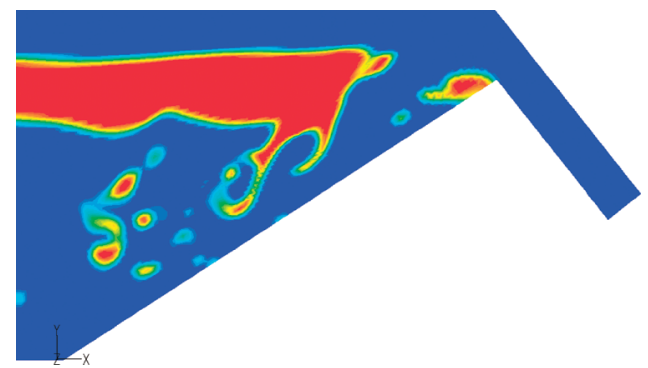

Fig. 3. Entrainment of the lighter phase in the CFD-model.

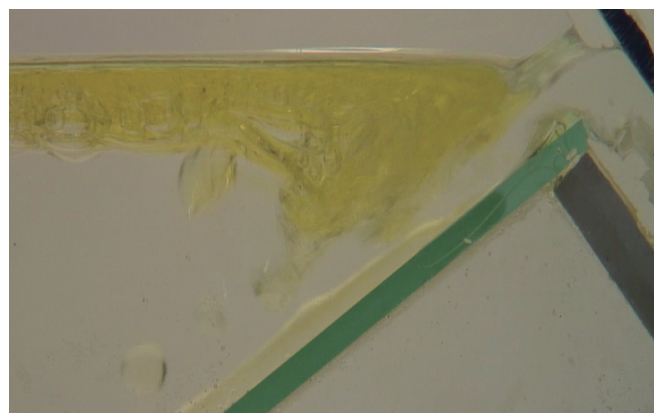

Fig. 4. Entrainment in the physical model.

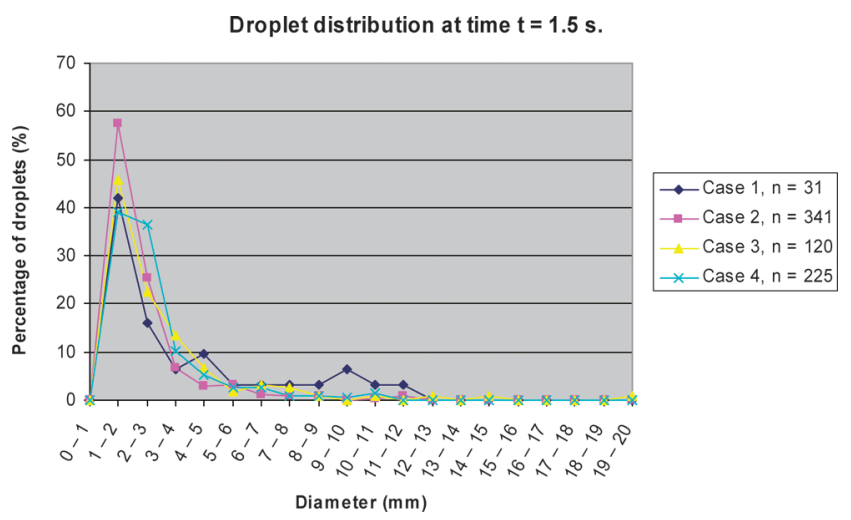

Fig. 5. Distribution of the formed droplets at $t=1.5 \mathrm{~s}$ for oil-water system.
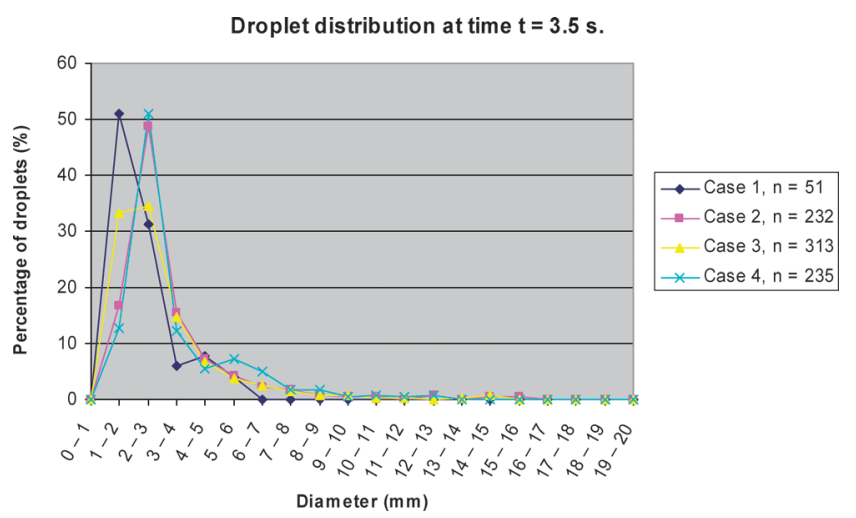

Fig. 6. Distribution of the formed droplets at $t=3.5 \mathrm{~s}$ for oil-water system.

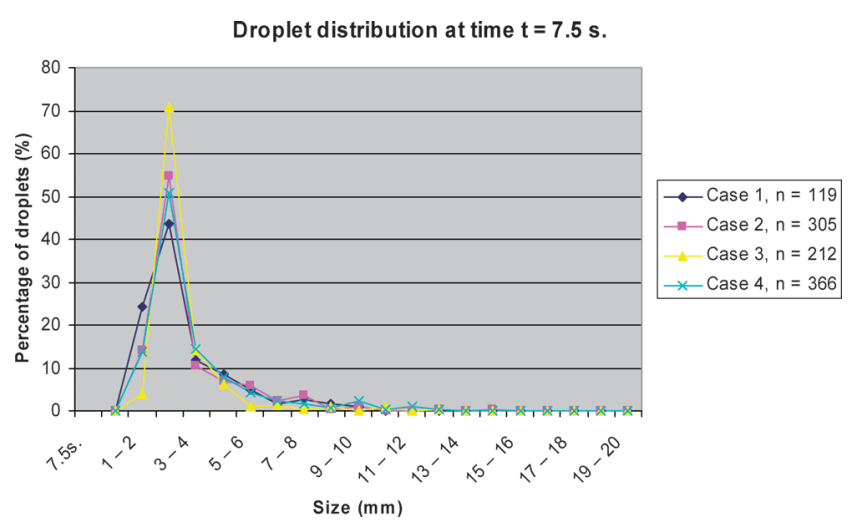

Fig. 7. Distribution of the formed droplets at $t=7.5 \mathrm{~s}$ for oil-water system.

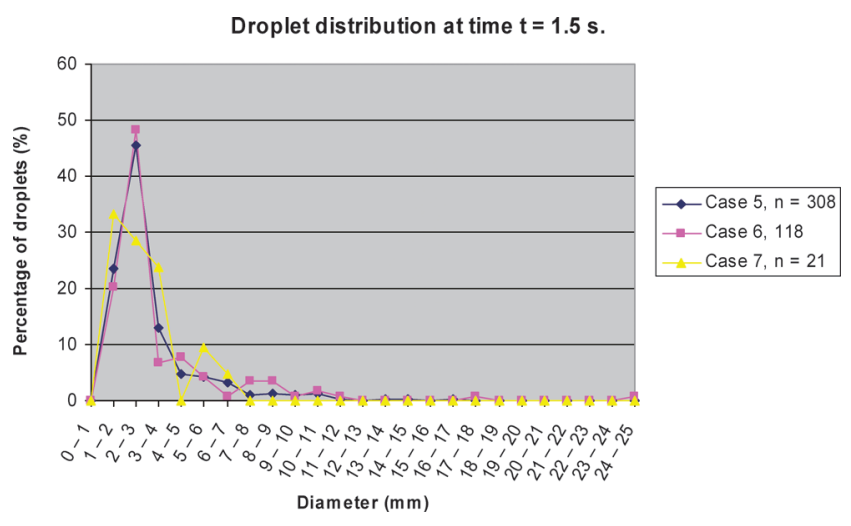

Fig. 8. Distribution of the formed droplets at $t=1.5 \mathrm{~s}$ for slag-steel system.

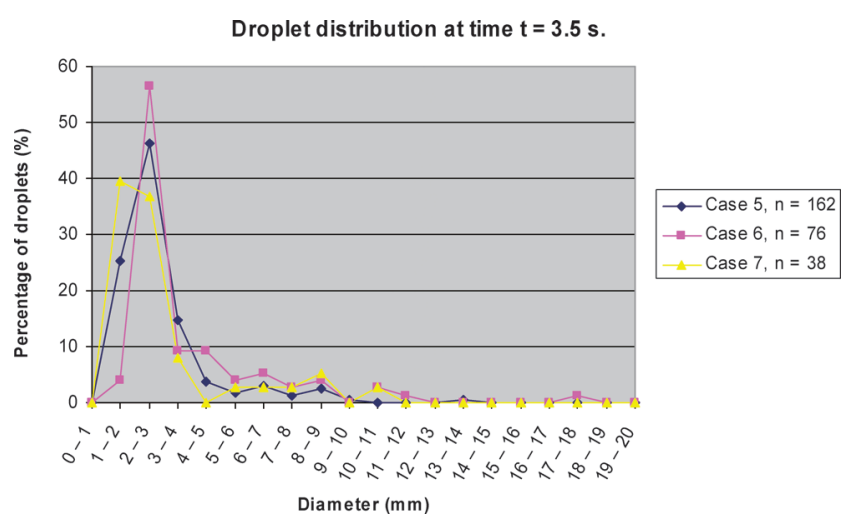

Fig. 9. Distribution of the formed droplets at $t=3.5 \mathrm{~s}$ for slag-steel system.

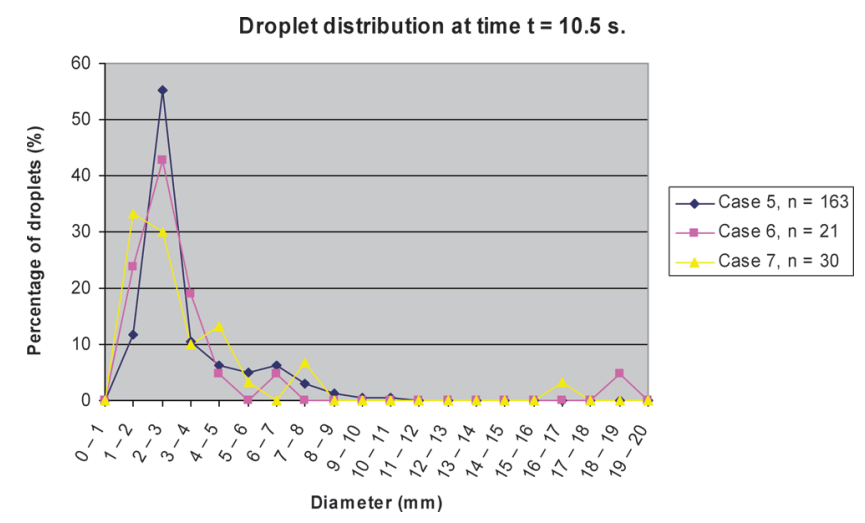

Fig. 10. Distribution of the formed droplets at $t=10.5 \mathrm{~s}$ for slag-steel system. 
Table 2. The properties used deriving the Eq. (14).

\begin{tabular}{|c|c|c|c|c|c|c|}
\hline & $\begin{array}{r}\begin{array}{r}\text { Width of the oil/slag } \\
\text { layer }\end{array} \\
\end{array}$ & $\begin{array}{r}\text { Interfacial } \\
\text { tension }\end{array}$ & Viscosity & $\begin{array}{r}\text { Density } \\
\text { difference }\end{array}$ & Critical velocity & $\begin{array}{r}\text { Weighted } \\
\text { average }\end{array}$ \\
\hline Case 1 & 0.005 & 0.01304 & 0.06134 & 94.00 & 0.285 & 2.78 \\
\hline Case 2 & 0.005 & 0.01295 & 0.14980 & 130.00 & 0.361 & 2.95 \\
\hline Case 3 & 0.015 & 0.01304 & 0.06134 & 94.00 & 0.324 & 3.06 \\
\hline Case 4 & 0.015 & 0.01295 & 0.14980 & 130.00 & 0.444 & 3.13 \\
\hline Case 5 & 0.015 & 0.50 & 0.18 & 4150.00 & 0.80 & 3.12 \\
\hline Case 6 & 0.015 & 0.75 & 0.18 & 4150.00 & 0.80 & 3.38 \\
\hline Case 7 & 0.015 & 1.05 & 0.18 & 4150.00 & 0.80 & 3.63 \\
\hline
\end{tabular}

Table 3. Average droplet diameters ( $\mathrm{mm})$.

\begin{tabular}{|l|r|r|r|r|}
\hline & $\begin{array}{r}\text { Present } \\
\text { model }\end{array}$ & Wei \& Oeters & Asai & Savolainen et al. \\
\hline Case 1 & 2.78 & 6.50 & 13.03 & 6.75 \\
\hline Case 2 & 2.95 & 5.50 & 11.04 & 7.50 \\
\hline Case 3 & 3.06 & 6.50 & 13.03 & 8.22 \\
\hline Case 4 & 3.13 & 5.50 & 11.04 & 8.50 \\
\hline Case 5 & 3.12 & 6.10 & 12.14 & - \\
\hline Case 6 & 3.38 & 7.50 & 14.87 & - \\
\hline Case 7 & 3.63 & 8.80 & 17.59 & - \\
\hline
\end{tabular}

The Table 3 represents the average droplet diameter calculated using Eqs. (14), (15) and (16) and also the results from the physical modelling by Savolainen et $a l^{5)}$

According to the Eqs. (15) and (16) the sizes are much bigger than those simulated by the present model. Also the average diameter given by the physical model is much bigger. The difference between the results given by Eqs. (14) and (15), (16) may be due to the fact that the oil/slag viscosity and width of oil/slag layer are neglected in Eqs. (15) and (16). The Eq. (15) seems to be working in the experiment made by Wei and Oeters. ${ }^{\text {) }}$ This might be due to the fact that the density difference between phases used in the experiment was small. The difference between the physical model and present CFD model may occur because the droplet diameters are measured from photographs which causes that the smallest droplets cannot necessarily be measured. Also the number of measured droplets in different cases is $7-10$ which is much less than in Cases 1-4 as can be seen from Figs. 5-7.

Wei and Oeters also give an equation for the critical velocity $^{6)}$

$$
u_{\text {crit }}=\left(\frac{3}{8}\right)^{1 / 2} \cdot\left(\frac{2}{3} \sigma \cdot g \cdot\left(\rho_{m}-\rho_{s}\right) \cdot \cos \alpha\right)^{1 / 4} \ldots
$$

According to Eq. (17) the critical velocity in Cases 1 and 3 is $0.133 \mathrm{~m} / \mathrm{s}$ and in Cases 2 and $40.147 \mathrm{~m} / \mathrm{s}$. These velocities are much slower than the ones defined by physical modelling.

Xiao et al. have presented the modified Weber number ${ }^{11)}$ which can be used as a criterion for the emulsification. The criterion gives a limit that emulsification could happen, that is

$$
\mathrm{We}=\frac{u_{\text {crit }} \cdot \rho_{s}}{\left(g \cdot \sigma \cdot\left(\rho_{m}-\rho_{s}\right)\right)^{1 / 2}} \geq 12.3
$$

When used the critical velocity given by the Eq. (17), we obtain $\mathrm{We}=4.61$ for all the water-oil system. That is much lower than the criterion given above which may also indicate that the effects of oil/slag viscosity and width of the oil/slag cannot be ignored.

\section{Conclusions}

Purpose of the present CFD-model was to study the droplet formation by simulating four different oil-water and three different slag-metal cases. The results from CFD calculations showed that the dominant droplet size in oilwater cases is between $2-3 \mathrm{~mm}$. Approximately $50-70 \%$ of droplets are of that size. In slag-metal cases the dominant size varies between $1-2 \mathrm{~mm}$ and $2-3 \mathrm{~mm}$. Especially in cases in which the interfacial tension between slag and metal is high the dominant size continues to vary. Also the amount of entrained droplets in these cases is lower.

The weighted average for the droplet diameter was also calculated for every case. That varies between 2.78 and $3.63 \mathrm{~mm}$. An equation for approximating the droplet size was derived by making a linear fitting to the weighted averages given by the model. The values given by the equation were compared to results given by equations derived by Wei and Oeters ${ }^{6}$ and Asai. ${ }^{10)}$ The results were also compared to results from physical modeling made by Savolainen et al. ${ }^{5)}$ The average droplet sizes given by the present model appeared to be much smaller than in those studies.

\section{Acknowledgements}

This research was financially supported by Finnish Funding Agency for Technology and Innovation and Outokumpu Stainless, which are kindly acknowledged by the authors. The authors would also like to thank Paavo Hooli, Pentti Kupari and Veikko Juntunen from Outokumpu Stainless, Mika Järvinen from Helsinki University of Technology and Olli Mattila from University of Oulu for many discussions and comments concerning the topic.

\section{REFERENCES}

1) A. W. Cramb: 13th Process Technology Conf. Proc., ISS, Warrendale, PA, (1995), 327.

2) A. W. Cramb, Y. Chung, J. M. Harman, A. Sharan and I. Jimbo: Iron Steelmaker, (1997), 77.

3) A. W. Cramb and I. Jimbo: Scaninject VII, MEFOS, Sweden, (1995), 89. 
4) J. M. Harman and A. W. Cramb: Steelmaking Conf. Proc., 79 (1996), 773.

5) J. Savolainen, T. Fabritius and O. Mattila: ISIJ Int., 49 (2009), No. 1, 29.

6) T. Wei and F. Oeters: Steel Res., 63 (1992), No. 2, 60

7) J. Mietz, S. Schneider and F. Oeters: Steel Res., 62 (1991), No. 1, 10.

8) M. Iguchi, Y. Sumida, R. Okada and Z. Morita: ISIJ Int., 34 (1993), No. 2, 164.

9) S. Asai: 100th and 101st Nishiyama Memorial Seminar, ISIJ, Tokyo, (1984), 67, 90.

10) H. Lachmund, Y. Xie, T. Buhles and W. Pluschkell: Steel Res., 74 (2003), No. 2, 77.

11) Z. Xiao, Y. Peng and C. Liu: Chin. J. Mater. Sci. Technical, 3 (1987), 187.

12) L. Jonsson and P. Jönsson: ISIJ Int., 36 (1996), No. 9, 1127.
13) M. A. T. Andersson, L. T. I. Jonsson and P.G. Jönsson: ISIJ Int., 40 (2000), No. 11, 1080 .

14) J. Smagorinsky: General Circulation Experiments with the Primitive Equations. I. The Basic Experiment, Month. Wea. Rev., 91: 99-164, (1963).

15) T. M. J. Fabritius: Doctoral Thesis, University of Oulu, Oulu, (2004), 63.

16) Slag Atlas, 2nd edition by Verein Deutscher Eisenhuttenleute (VDEh), Verlag Stahleisen GmbH, Düsseldorf, (1995), 606.

17) A. Kärnä, L. Hekkala, T. Fabritius, J. Riipi and M. Järvinen: Scanmet III, 3rd Int. Conf. on Process Development in Iron and Steelmaking, Luleå, Sweden, (2008), 155.

18) L. A. Girifalco and R. J. Good: Phys. Chem., 61 (1957), 904.

19) T. Tanaka, T. Kitamura and A. Back: ISIJ Int., 46 (2006), 400.

20) J. Riipi and T. Fabritius: ISIJ Int., 47 (2007), 1575. 